\title{
Long-term management of thrombocytosis in essential thrombocythaemia
}

\author{
Gunnar Birgegård
}

Received: 4 April 2008 / Accepted: 4 June 2008 / Published online: 16 July 2008

(C) The Author(s) 2008

\begin{abstract}
Essential thrombocythaemia (ET) is an acquired myeloproliferative disorder with a prolonged clinical course and a near-normal life expectancy. Therapy is stratified according to risk of thrombohaemorrhagic events. In highrisk patients, platelet reduction is generally recommended. In intermediate-risk patients, therapy should be considered depending on the severity of associated risk factors, especially cardiovascular. In low-risk patients, a watchand-wait approach is appropriate. Hydroxycarbamide is generally first-line therapy. Concerns for possible leukemogenicity make anagrelide or interferon- $\alpha$ possible choices in younger patients and those who are resistant or intolerant to hydroxycarbamide. Each pharmacotherapy is associated with specific long-term risks and benefits. The potential risk of major bleeding is the main drawback of aspirin. Hydroxycarbamide is an established, effective drug for ET, but it may increase the risk of transformation to acute myeloid leukaemia and may give mucocutaneous ulcers. Anagrelide is a licensed treatment that also reduces platelet counts and is generally well tolerated, with evidence that some common side effects diminish over time. Anagrelide can have cardiac effects due to inhibition of phosphodiesterase III and therefore requires cautious use in patients with cardiac insufficiency. There is no evidence of leukaemogenicity with anagrelide or interferon- $\alpha$ therapy. Interferon- $\alpha$ is the only treatment suitable for use during pregnancy, although it is not licensed in ET. While it is
\end{abstract}

Financial support: This manuscript was supported by an unrestricted educational grant from Shire.

\section{G. Birgegård $(\bowtie)$}

Department of Haematology, Division of Medicine, Institution for Medical Sciences, University Hospital, Uppsala 75185, Sweden

e-mail: gunnar.birgegard@medsci.uu.se effective for platelet reduction, the use of interferon- $\alpha$ is restricted by psychiatric side effects. Our knowledge of the optimum pharmacotherapy for each patient with ET continues to evolve through research and clinical trials, particularly into the molecular basis of the disease.

Keywords Essential thrombocythaemia - Anagrelide . Hydroxycarbamide · Interferon · Myeloproliferative disorder

\section{Introduction}

Essential thrombocythaemia (ET) is an acquired myeloproliferative disorder (MPD), characterised by persistent peripheral thrombocytosis and a tendency for thrombosis and haemorrhage [1]. For example, in a study of 93 patients with ET, at a median follow-up of 70 months, $16 \%$ of patients developed thrombosis, $14 \%$ developed haemorrhage and $17 \%$ developed microvascular complications [2]. ET can proceed in some cases to myelofibrosis, acute myeloid leukaemia (AML), myelodysplastic syndromes (MDS) or polycythaemia vera (PV) [3]. The estimated annual incidence of ET based on World Health Organization (WHO) criteria is $1-2.5 / 100,000$ individuals [4]. However, the true incidence is likely to be higher as many patients are without symptoms, and thus undiagnosed. Even though ET is a rare disease, the prevalence is high at 30/ 100,000 general population [1], reflecting the near-normal life expectancy of patients with the condition [5].

Several lines of evidence suggest that ET is a heterogeneous disease entity, though the existence of distinct subgroups is difficult to validate. Molecular evidence includes the patient's JAK2 mutation status (i.e. the presence or absence of the Janus kinase 2 mutation $J A K 2 V 617 F$ ) [3], variation in X-chromosome inactivation 
patterns in females [6] and differences in PV rubra vera-1 (PRV1) mRNA expression (discriminating two types of ET) [7], while immunohistochemical evidence includes heterogeneous c-mpl expression [8]. Differences have also been observed between patients with ET in the growth of erythropoietin-independent colonies (EEC). In a study of molecular markers, growth of EEC was observed in 50$69 \%$ of ET patients [7, 9]. Furthermore, as a group, ET patients with the $J A K 2 \mathrm{~V} 617 F$ mutation and/or low serum erythropoietin levels seem to have a more PV-like phenotype with slightly higher white blood cell counts and haemoglobin levels $[3,10,11]$.

\section{Diagnosis}

The diagnosis of ET includes detection of specific changes in bone marrow morphology, as well as exclusion of secondary thrombocytosis caused by other conditions [12]. Recently, an advisory group to the WHO proposed revised diagnostic criteria for ET (Table 1) [12]. Using these criteria, diagnosis is supported by demonstration of a clonal marker of the condition (e.g. JAK2V617F, present in approximately $50 \%$ of ET patients) [3]; however, identification of this mutation cannot differentiate between ET and other MPDs. Several investigators suggest that some ET patients diagnosed according to the guidelines of the Polycythaemia Vera Study Group actually have an early stage chronic primary myelofibrosis (PMF-0 or 'false ET') $[13,14]$. This prefibrotic condition is known to progress to overt myelofibrosis in a high proportion of patients, thus differing from 'true ET' which does not [15-17]. If this distinction is valid, it is an important consideration when evaluating treatment strategies. However, the feasibility of distinguishing ET from PMF-0 is not generally accepted among pathologists in clinical practice [18].

Table 1 New World Health Organization (WHO) proposed classification for essential thrombocythaemia [12]

All the following criteria must be met to diagnose essential thrombocythaemia:

- Sustained platelet count $\geq 450 \times 10^{9} / 1$ (reduced from $\geq 600 \times 10^{9} / 1$ )

- Bone marrow biopsy specimen showing proliferation mainly of the megakaryocytic lineage with increased numbers of enlarged, mature megakaryocytes; no significant increase or left-shift of neutrophil granulopoiesis or erythropoiesis

- Does not meet the WHO criteria for polycythaemia vera, primary myelofibrosis, chronic myelogenous leukaemia, myelodysplastic syndromes or other myeloid neoplasms

- Demonstration of $J A K 2 V 617 F$ mutation or other clonal marker, or in the absence of a clonal marker, no evidence for reactive thrombocytosis

\section{The ideal therapeutic agent?}

A number of pharmacotherapies have been investigated for use in ET. The ideal therapeutic treatment should rapidly lower platelet counts to normal levels, reduce ET-related complications and symptoms, have limited side effects and no long-term safety concerns. Long-term benefits and risks of pharmacotherapy are of particular relevance to patients with ET, who require prolonged treatment over a lifetime. This article considers the long-term effects of several ET treatment options, focusing on the anti-platelet agent, aspirin, and three cytoreductive therapies: hydroxycarbamide, anagrelide and interferon- $\alpha$. Taking these findings into consideration, a risk-based treatment algorithm for ET is proposed.

\section{Literature search}

This article contains information from a number of sources, including relevant searches of PubMed (conducted on 14 November 2007), the author's own reference database and the reference lists of recent review articles. It is not intended as a systematic review.

\section{Acetylsalicyclic acid (aspirin)}

Since it was first synthesised in 1897, the use of aspirin has extended from analgesia to encompass prevention of cardiovascular events such as myocardial infarction and ischaemic stroke [19]. Theoretically, aspirin also has a place in the management of ET, particularly as it has been shown to suppress excess thromboxane synthesis [20], evident in patients with ET and PV [20,21]. Several studies have confirmed this theory, showing that aspirin reduces thrombotic complications associated with ET $[22,23]$ as well as microvascular events (e.g. neurological symptoms and erythromelalgia) [24, 25].

The only randomised controlled trial investigating use of aspirin in this area was performed in patients with PV, a related MPD [26], which calls into question the direct applicability of the results. In the placebo-controlled European Collaboration on Low-dose Aspirin in PV (ECLAP) study, low-dose aspirin $(100 \mathrm{mg} /$ day $)$ significantly reduced the risk of thrombotic complications (non-fatal myocardial infarction and stroke, death from cardiovascular causes, pulmonary embolism and major venous thrombosis) [26].

Any long-term therapeutic benefit of aspirin should be weighed against the potential risk of a major bleeding episode and gastrointestinal side effects. The relative risk of major bleeding with aspirin was 1.62 in the ECLAP study, which was consistent with results in non-PV patients [26]. 
Use of aspirin should therefore be avoided in patients with a history of bleeding or with very high platelet levels (greater than $1,500 \times 10^{9} / 1$ ) because of an increased risk of haemorrhage [27]. Taking the observational and theoretical evidence into account, aspirin may have a role for the management of ET, particularly for patients at low risk of haemorrhagic complications. Noteworthy, however, is that health economic studies calculating the value of health gain versus the loss of health due to complications of aspirin therapy have not been undertaken in ET.

\section{Hydroxycarbamide}

Hydroxycarbamide, also known as hydroxyurea, is a nonspecific, cytotoxic, myelosuppressive agent that is used to treat all MPDs, including ET. Its mechanism of action involves inhibition of ribonucleotide diphosphate reductase activity, thus blocking the cell cycle at the $\mathrm{G}_{1} / \mathrm{S}$ phase and resulting in cell death [28].

Hydroxycarbamide is an established drug with proven platelet-reducing efficacy [29-33] and is generally well tolerated [31, 32]. Results from two randomised controlled trials confirm that hydroxycarbamide reduces the risk of thrombotic events in high-risk patients with ET [29, 30]. The Italian study by Cortelazzo et al., in which patients were randomised to receive hydroxycarbamide $(n=56)$ or no myelosuppressive therapy $(n=58)$, reported the number of thrombotic episodes to be significantly lower in the hydroxycarbamide group than in the control group $3.6 \%$ and $19.0 \%$, respectively; $p=0.003$ ) [29]. Noteworthy is that about $70 \%$ of patients in both groups also received antiplatelet prophylaxis. The United Kingdom Medical Research Council Primary Thrombocythaemia 1 study (MRC PT-1) compared hydroxycarbamide plus aspirin $(n=404)$ with anagrelide plus aspirin $(n=405)$ [30]. Rates of major arterial and venous thrombosis in the hydroxycarbamide arm $(4.2 \%$ and $3.5 \%$, respectively) were similar to those observed in the hydroxycarbamide group of the Cortelazzo study [29, 30]. The incidence of venous thrombosis was significantly lower in the anagrelide arm than in the hydroxycarbamide arm $(p=0.006)$, whereas the incidence of arterial thrombosis was lower in the hydroxycarbamide arm $(p=0.004)$. However, the reasons behind these observations are unclear. Five patients developed myelofibrosis in the hydroxycarbamide group versus 16 in the anagrelide group; raising the possibility that hydroxycarbamide may give better protection against fibrosis. Significantly fewer haemorrhagic events occurred in the hydroxycarbamide group than in the anagrelide group, 8 versus 22, respectively $(p<0.008)$. The latter finding may be due to a synergistic effect between anagrelide and aspirin when given concomitantly. No significant difference in the frequency of minor bleedings between treatment groups was observed [30]. It is noteworthy that a separate randomised controlled investigation (ANAHYDRET study) compared hydroxycarbamide and anagrelide in 258 previously untreated ET patients diagnosed according to the WHO criteria [34]. The 12-month findings, reported at the American Society of Hematology congress in 2007, showed no significant difference in the incidence of thromboembolic or haemorrhagic events (major events 8 versus 8 and minor events 22 versus 23 for thromboembolic and haemorrhagic events, respectively) between the hydroxycarbamide and anagrelide arms, suggesting noninferiority for anagrelide. However, statistically low numbers preclude a firm conclusion at this timepoint [34].

There is strong evidence to suggest that concomitant or sequential use of hydroxycarbamide and an alkylating agent or radioactive phosphorous may increase the risk of malignant transformation in MPDs, possibly due to the radiosensitising effect of hydroxycarbamide [35-39]. This theory is supported by mechanism of action studies, which show that hydroxycarbamide prevents de novo DNA synthesis and repair [40]. Interestingly, the bone marrow of hydroxycarbamide-treated patients shows a dysplastic appearance, including left-shifting of myelopoiesis, macrocytosis of red cells and dysplasia of megakaryocytes, which is not seen with non-cytostatic drugs [41]. In clinical studies with more than 96 months median follow-up, transformation to AML/MDS occurred in $0-22 \%$ of patients with ET/PV treated with hydroxycarbamide as the sole therapeutic agent $[33,37,42-46]$. The only long-term study designed to investigate this endpoint shows that transformation to AML in hydroxycarbamide- or pipobroman-treated patients generally occurs after 10 or more years' therapy, with the incidence reaching 10-12\% after 12 years [45]. In conclusion, the leukaemogenicity of hydroxycarbamide remains a concern that has not been diminished by recent data.

The most common side effects of hydroxycarbamide are granulocytopaenia and anaemia [47], especially after longterm treatment. Fever of unknown aetiology has also been observed following initiation of hydroxycarbamide therapy [48-50]. Cutaneous manifestations are commonly reported by patients receiving long-term hydroxycarbamide therapy and are the most frequent reason for treatment cessation [51-53]. Cutaneous complications include alopecia, xerosis and scaling, atrophy of the skin and subcutaneous tissues, skin and nail hyperpigmentation, and cutaneous and mucocutaneous ulceration [51, 52]. Furthermore, an association between long-term hydroxycarbamide therapy and multiple skin tumours, including squamous and basal cell carcinomas, has also been reported [54]. The lower-limb ulcers caused by hydroxycarbamide are often painful, and treatment must be withheld to allow the ulcers to heal, but 
this occurs slowly and poorly, occasionally requiring grafting $[55,56]$. In one study, 12 out of 133 patients $(9.0 \%)$ receiving hydroxycarbamide developed leg ulcers, requiring a switch of treatment in ten of these patients [46]. Withdrawal rates of $8-20 \%$ due to adverse effects have been reported in trials $[30-32,46]$. According to experts in the field [57, 58] and evidence-based guidelines [59], hydroxycarbamide is considered to be the first-choice cytoreductive therapy in high-risk patients with ET. However, approximately $15 \%$ of patients receiving hydroxycarbamide either do not achieve the desired reduction in platelet counts or develop unacceptable side effects [30-33, 46, 60]. In an attempt to standardise the definition of resistance and intolerance to hydroxycarbamide, thus when to stop treatment and switch to an alternative therapy, a working group consensus definition has recently been published (Table 2) [61].

\section{Anagrelide}

Anagrelide is a cytoreductive agent, with a selective effect on the megakaryocyte cell lineage [62]. It reduces platelet production by inhibiting megakaryocyte colony development, thus reducing megakaryocyte size, ploidy and maturation [63]. Several studies have shown that it effectively lowers platelet counts (overall response rate of 76-94\%) and reduces ET-associated complications and symptoms [63-72]. Anagrelide has been shown in trials to be as effective as hydroxycarbamide, interferon- $\alpha$ and alkylating agents in reducing platelet counts, without the added complication of alkylating or cytotoxic properties [73], and can be used in patients who are intolerant or resistant to these cytoreductive agents [64].

Anagrelide is not mutagenic [74], and there is no known evidence to suggest that it is leukaemogenic [75]. In a longterm retrospective analysis, anagrelide did not result in

Table 2 Consensus definition of clinical resistance or intolerance to hydroxycarbamide in patients with essential thrombocythaemia (adapted from Barosi et al. [61])

Resistance/intolerance to hydroxycarbamide requires fulfilment of at least one of the following criteria:

\begin{tabular}{|c|c|}
\hline $\begin{array}{l}\text { Platelet count } \\
\text { of: }\end{array}$ & $\begin{array}{l}>600,000 / \mu \mathrm{l} \text { after } 3 \text { months of treatment with at } \\
\text { least } 2 \mathrm{~g} / \text { day hydroxycarbamide }{ }^{\mathrm{a}} \\
>400,000 / \mu \mathrm{l} \text { and leukocytes }<2,500 / \mu \mathrm{l} \text { at any dose } \\
\text { of hydroxycarbamide } \\
>400,000 / \mu 1 \text { and haemoglobin }<10 \mathrm{~g} / \mathrm{dl} \text { at any dose } \\
\text { of hydroxycarbamide }\end{array}$ \\
\hline \multicolumn{2}{|c|}{$\begin{array}{l}\text { Presence of leg ulcers or other unacceptable mucocutaneous } \\
\text { manifestations at any dose of hydroxycarbamide }\end{array}$} \\
\hline Fever related t & ydroxycarbamide \\
\hline
\end{tabular}

${ }^{\mathrm{a}} 2.5 \mathrm{~g}$ /day in patients with a body mass of $>80 \mathrm{~kg}$ excess conversion to AML, and no ET patient receiving anagrelide for more than 3 years transformed [64]. Moreover, in a study with a mean follow-up of 12.5 years, leukaemic transformation did not occur in any of the $39 \mathrm{ET}$ patients treated with anagrelide [76].

Anagrelide is considered effective for reducing the incidence of thromboembolic and haemorrhagic complications. However, this effect has not been investigated in a placebo-controlled study. Supporting evidence rests mainly on the comparison with hydroxycarbamide; in particular, the study by Cortelazzo et al. [29] showing a reduction in thrombotic events with cytoreductive treatment, and the results of the PT-1 study [30], demonstrating a similar incidence of thrombotic events in the anagrelide and hydroxycarbamide arms to that reported in the Cortelazzo study. These two studies differed in terms of inclusion criteria and the use of aspirin; however, the incidence of thrombosis was the same in both hydroxycarbamide arms, indicating similarity of the population. The ANAHYDRET study demonstrated non-inferiority of anagrelide (for efficacy and ET-related complications) compared with hydroxycarbamide for the treatment of ET patients at 12 months follow-up $(p<0.025)$ [34]. Furthermore, in a study of 79 patients with ET, anagrelide significantly reduced the rate of major thromboembolic complications compared with the pre-treatment period $(p=0.0455)$ [65]. However, a clear clinical benefit in terms of haemorrhagic events has not yet been convincingly demonstrated.

The most common side effects of anagrelide include headache (13-35\%) and tachycardia (9-21\%), which arise due to the inhibitory properties of anagrelide on phosphodiesterase III $[65,66,69,70,73,77]$. The majority of common side effects are mild or moderate (e.g. WHO grade 1 or 2) and manageable [63-66, 70, 72, 77], with the frequency and severity dose-dependent [63]. The incidence of serious side effects is higher in patients aged 60 years or older than in patients younger than 60 years [64]. Aggravation of cardiac insufficiency is a rare but important side effect, and special caution is advised in patients with previous cardiac failure [76, 78]. Anagrelide lowers red blood cell count by approximately $10 \%$ in about $30 \%$ of patients $[63,79]$, thought to be due to its well-known vasodilatory properties [63]. Anaemia was detected in about $50 \%$ of patients in a study by Penninga et al. but was mild and not clinically apparent in most [66]. Lowgrade anaemia was shown to persist during a 2-year followup study, but not to progress.

Appropriate management of side effects may lead to successful long-term acceptance of medication. In several studies, the majority of side effects with anagrelide occurred within 1 month of starting therapy [65, 66, 68, $70,71]$, with evidence showing that they subsided during continued treatment $[65-71,77,80]$. This effect is clearly 
illustrated in the study by Storen and Tefferi involving 35 patients younger than 50 years with ET [67]. Comparing initial (less than 3 months) and longer-term (over 3 months) anagrelide treatment, the incidence of headache was reduced from $34.2 \%$ to $5.7 \%$, tachycardia from $22.8 \%$ to $8.5 \%$, oedema from $14.2 \%$ to $5.7 \%$ and diarrhoea from $8.5 \%$ to $0 \%$ [67]. In contrast, a study by Birgegard et al. showed that the intensity of side effects remained the same in some patients with long-term treatment [63]. These findings suggest that it may be beneficial to inform patients of the possible reduction in side effects with time in order to improve compliance, especially in the early stages of treatment. Alternatively, it is feasible that this observed reduction was due to the withdrawal of patients who cannot tolerate anagrelide, hence only those patients experiencing milder side effects were recorded. However, in the study by Storen and Tefferi, no patients were lost to follow-up; therefore, it appears that the reduction in side effects might be related to improved tolerance to treatment with time.

For some ET patients, side effects can be prolonged and may lead to discontinuation of therapy: $0-50 \%$ of patients were withdrawn from anagrelide treatment in published studies $[63,64,68,69,80]$, some because of lack of response and others because increasing the dose to an effective level was hindered by side effects.

\section{Interferon- $\alpha$}

The interferon cytokine family demonstrates a wide range of biological properties, such as immune activation, as well as anti-proliferative and cell differentiation effects [81]. Based on these properties, interferon- $\alpha$ was first investigated for the treatment of ET in the late 1980s; however, it has never received an EU licence for a platelet reduction indication. The mechanism of action of interferon- $\alpha$ is thought to relate to its anti-proliferative effects on megakaryocytes, with reduction in platelet half-life also a contributing factor [82].

Interferon- $\alpha$ is effective in reducing platelet counts, with a mean overall response rate of $84.6 \%$ [59]. There has been no randomised comparison of interferon- $\alpha$ with other conventional therapies. Nevertheless, interferon- $\alpha$ is used off-label as a platelet-reducing alternative agent in MPDs, and is the only drug suitable for use during pregnancy [59]. It is of note that interferon- $\alpha$ is not known to be leukaemogenic [75].

Recent results in patients with PV indicate that interferon- $\alpha$ can reduce the percentage of cells expressing the $J A K 2$ mutant allele (i.e. the JAK2V617F allele burden) [8385]. The biological and clinical significance of these results are unclear, and larger-scale studies are required to confirm the original findings. To date, no similar results have been published in patients with ET.
Common side effects of interferon- $\alpha$ include influenzalike symptoms, nausea, diarrhoea, myalgia, depression and fatigue $[59,86]$. Side effects occur in nearly all patients at the start of treatment, but they generally abate [59]. For example, in the study by Yataganas et al. investigating the use of interferon- $\alpha$ in 18 patients with an MPD (nine with ET), influenza-like symptoms (e.g. fever higher than $38^{\circ} \mathrm{C}$ ) lasted a maximum of 4-8 days following treatment initiation [87]. Despite this abatement, dropout rates between $15 \%$ and $66 \%$ have been reported, most commonly around 25\% [88-90].

Given its immunomodulatory properties, interferon- $\alpha$ may result in symptomatic episodes of autoimmune disease such as hypothyroidism [91]. There have been reports of autoimmune thyroiditis [92], arthritis [93], hypertriglyceridaemia [94] and ischaemic optic neuropathy [95]. Mood disorders (depression/mania) are a well-documented side effect of interferon- $\alpha$ treatment [96-98], and limit the clinical utility of this agent in the treatment of ET.

The use of pegylated-interferon- $\alpha$ has also been investigated for the treatment of MPDs. This agent is formulated from interferon- $\alpha$ by attaching high molecular weight polymers of ethylene glycol [99]. Such chemical modification increases serum half-life and reduces renal excretion, thus allowing weekly, rather than daily, administration. Pegylated-interferon- $\alpha$ has been shown to effectively control platelet count and disease symptoms in patients with MPDs, including ET [88, 100-102]. However, in two studies of 38 and 42 patients with an MPD, pegylatedinterferon- $\alpha$ had a similar tolerability profile to conventional interferon- $\alpha$, with $26 \%$ and $50 \%$ of patients stopping therapy due to side effects and the level of toxicity limiting the duration of therapy $[101,102]$.

\section{Risk stratification for treatment management}

ET is a chronic condition with a prolonged clinical course that cannot currently be cured. Management, therefore, relies on the prevention of serious complications, specifically thrombohaemorrhagic events, through reduction of the platelet count or by altering platelet function. Management is stratified according to risk, categorised as high, intermediate and low, though the exact definition varies by investigator and country. In addition to traditional risk factors, which include previous thrombosis or major bleeding, age and elevated platelet count, other less traditional risk factors have also been suggested that may influence treatment decisions. They include cardiovascular risk factors and molecular markers (e.g. presence of PRV-1 or $J A K 2$ mutation) [103]. Whether the JAKV2617F mutation should be part of the risk stratification remains an area of uncertainty. Although evidence on whether the 
JAK2V617F mutation increases the risk of thrombotic complications is conflicting [104-108], overall it appears that having the mutation is associated with a slightly higher risk. Some studies have indicated an association between leukocytosis and increased risk of thrombosis [10, 109, $110]$, and one study showed in a time-dependent analysis that the increased risk was corrected by hydroxycarbamide treatment [10]. It is possible that the leukocyte count is a prognostic marker for the activity of the MPD, but it remains to be proven by further study whether it is an important marker for treatment efficacy. The evidence for raised leukocyte levels being a risk factor for survival in ET is growing, but intervention studies are needed before white blood cell counts can be a basis for treatment decisions.

Taking into account the available evidence and clinical experience for various ET treatments, a suggested treatment algorithm is presented in Fig. 1. The following risk factors are suggested to define high-risk ET patients: (1) previous thrombosis or major bleeding; (2) age older than 60 years; or (3) very high platelet count $\left(>1,500 \times 10^{9} / 1\right)$. Intermediate-risk ET patients are classified as those without high-risk criteria, but with hereditary thrombophilia or cardiovascular risk factors. Low-risk ET patients are without any of these risk factors.

For high-risk patients, hydroxycarbamide is standard therapy. However, due to the potential leukemogenicity of this drug, anagrelide or pegylated-interferon- $\alpha$ are possible alternative options in 'young' patients. This is a difficult issue and under much debate as currently no consensus has been reached upon evaluation of the available data. One has to bear in mind that ET patients have a near-normal life expectancy, which means that they may be subject to platelet-reducing therapy for many years. Prospective studies are needed to decide whether lowering of white blood cells is an important goal of treatment in ET, allowing risk/benefit decisions in the choice of treatment in younger patients. A watch-and-wait approach is recommended for low-risk patients, though low-dose aspirin may form part of the treatment strategy in this group. Aspirin should be avoided in patients with platelet counts exceeding $1,000 \times 10^{9} / 1$ and the combination of aspirin and anagrelide should be avoided in patients with previous major bleeding.

The platelet treatment goal is under debate. Previously, a standard goal was to lower platelet levels below $600 \times 10^{9} / 1$. However, this threshold appears to be based on the previous diagnostic platelet level of $>600 \times 10^{9} / 1$, rather than evidence from clinical studies. Although there is only sporadic evidence that a lower treatment goal would provide better protection against thrombosis, since the new WHO diagnostic criteria use a platelet cut-off level of $450 \times 10^{9} / 1$, in the current discussion a more stringent treatment goal of 400 or $450 \times 10^{9} / 1$ in ET patients has been suggested.

\section{Special treatment problems}

Patients may be partly unresponsive to any of the three common drugs for treating ET, or side effects may hinder a dose increase to an effective level. In these cases, combining two drugs may be an option. There are no studies exploring
Fig. 1 Proposed treatment algorithm for patients with essential thrombocythaemia. Reproduced from Birgegard G. European Journal of Haematology 2007; 79 (Suppl. 68): 27-31 with permission of Blackwell Publishing. $C V$, cardiovascular; $E T$, essential thrombocythaemia; $I F N$, interferon- $\alpha$. The age limit 60 years for the choice of firstline therapy is the personal opinion of the author

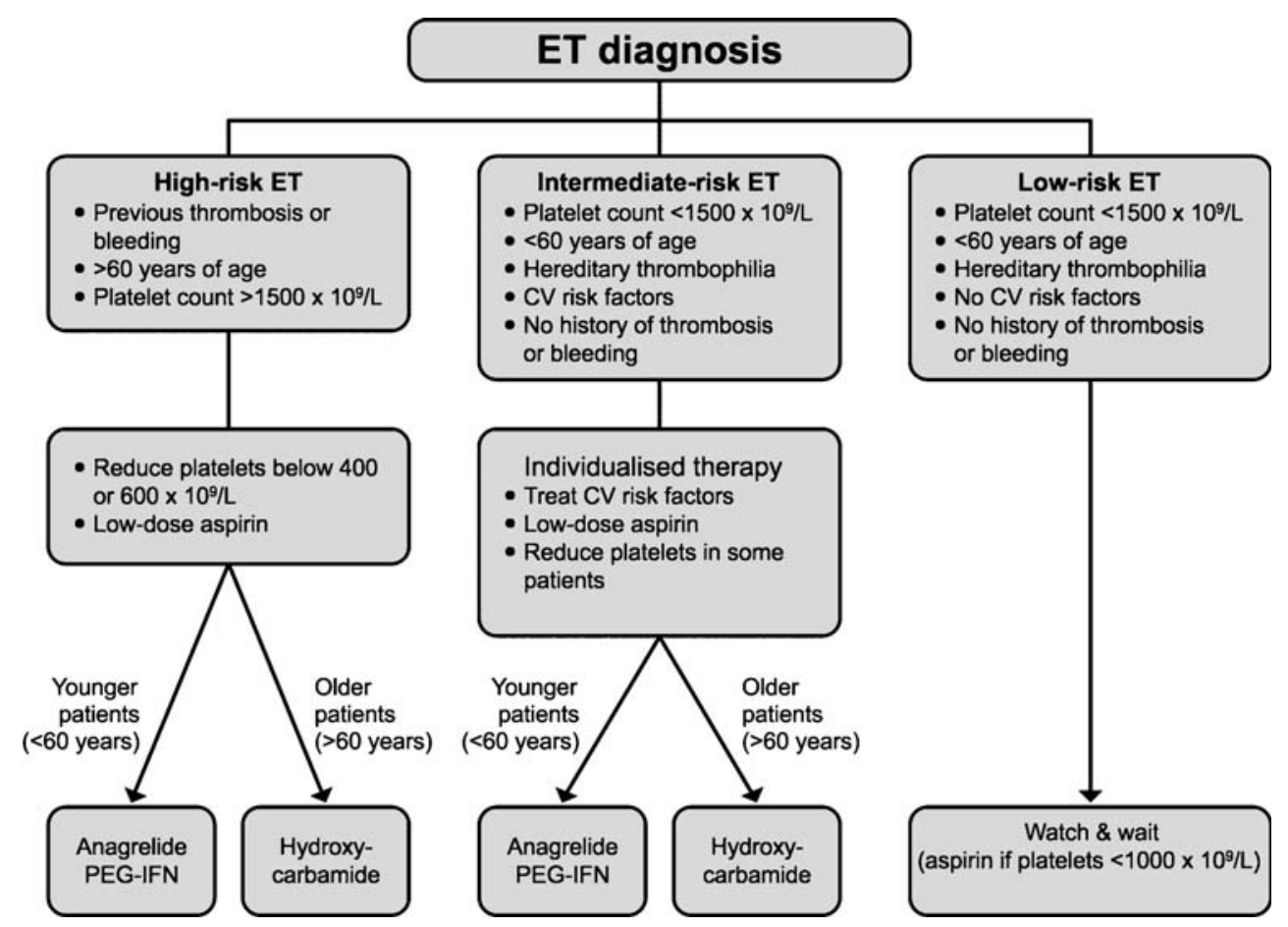


such combinations, nor is any combination therapy licensed for the treatment of ET, but in clinical practice it appears to be of good use. For example, a patient who develops anaemia or leukopenia from hydroxycarbamide may also benefit from receiving low-dose anagrelide, thus allowing the dose of hydroxycarbamide to be reduced and haemoglobin levels to be restored. Likewise, a combination of drugs may be beneficial for patients who cannot tolerate a dose increase of anagrelide or interferon- $\alpha$ to an effective level.

Patients intolerant to hydroxycarbamide, who either have cardiac insufficiency or are very old, constitute a special treatment problem. Anagrelide is not suitable in these patients, and neither is interferon- $\alpha$. In this situation, busulphan may be an option, in spite of its leukaemogenic properties. A course of busulphan may provide sustained remission over many months, and the likelihood of developing leukaemia before death from other causes is low. On the same grounds, radioactive phosphorous is also an option.

During pregnancy it is not unusual for platelet levels to fall, but if platelet-reducing therapy is needed, interferon- $\alpha$ is the only recommended drug [111].

\section{Possible future therapy developments}

MPDs are clonal diseases and the ultimate goal must be to find a cure. However, the treatment of MPDs is a developing field. The detection of the JAK2V617F mutation may offer the opportunity for drug development and also provide a molecular marker for treatment efficacy. In PV, the reduction in JAK2 allele burden with interferon- $\alpha$ treatment is of considerable interest [112], and similar findings have recently been found during hydroxycarbamide therapy in PV (personal communication). However, there have been no reports as to whether this is also true for ET. It is most likely that the $J A K 2 V 617 F$ mutation is not the only molecular event responsible for development of PV and, therefore, although $J A K 2$ inhibitors are of great interest, they are unlikely to provide a cure. This is especially relevant in ET, where only half of patients carry the mutation, almost exclusively in heterozygous form [3]. However, if $J A K 2$ inhibitors prove to be effective for reducing platelet numbers, the discussion will concern whether the expected high cost of such drugs is warranted for symptomatic treatment. One can, therefore, expect the current platelet-reducing agents to maintain their place in the therapy of ET for the foreseeable future.

\section{Conclusions}

The objective of ET treatment is to reduce the risk of thromboembolic and haemorrhagic complications associat- ed with the disorder. Treatment is given according to risk stratification: platelet reduction should be given in high-risk patients and selected intermediate-risk patients, whereas no treatment or aspirin should be used in low-risk patients. Hydroxycarbamide is currently first-line therapy in patients older than 60 years of age, whereas non-mutagenic drugs like anagrelide and interferon- $\alpha$ might be considered in younger patients and those clinically intolerant or resistant to hydroxycarbamide.

Acknowledgements Medical writing assistance was provided by Fishawack Communications and financial support was provided by Shire.

Conflicts of interest Prof. Dr Birgegård has received unrestricted research support from Schering-Plough and Shire, as well as fees for speaking assignments from Shire.

Open Access This article is distributed under the terms of the Creative Commons Attribution Noncommercial License which permits any noncommercial use, distribution, and reproduction in any medium, provided the original author(s) and source are credited.

\section{References}

1. Briere JB (2007) Essential thrombocythemia. Orphanet J Rare Dis 2:3 doi:10.1186/1750-1172-2-3

2. Jensen MK, de Nully Brown P, Nielsen OJ, Hasselbalch HC (2000) Incidence, clinical features and outcome of essential thrombocythaemia in a well defined geographical area. Eur J Haematol 65:132-139 doi:10.1034/j.1600-0609.2000.90236.x

3. Campbell PJ, Scott LM, Buck G, Wheatley K, East CL, Marsden JT et al (2005) Definition of subtypes of essential thrombocythaemia and relation to polycythaemia vera based on JAK2 V617F mutation status: a prospective study. Lancet 366:19451953 doi:10.1016/S0140-6736(05)67785-9

4. Sanchez S, Ewton A (2006) Essential thrombocythemia: a review of diagnostic and pathologic features. Arch Pathol Lab Med 130:1144-1150

5. Penninga EI, Bjerrum OW (2006) Polycythaemia vera and essential thrombocythaemia: current treatment strategies. Drugs 66:2173-2187 doi:10.2165/00003495-200666170-00003

6. Harrison CN, Gale RE, Machin SJ, Linch DC (1999) A large proportion of patients with a diagnosis of essential thrombocythemia do not have a clonal disorder and may be at lower risk of thrombotic complications. Blood 93:417-424

7. Griesshammer M, Klippel S, Strunck E, Temerinac S, Mohr U, Heimpel $\mathrm{H}$ et al (2004) PRV-1 mRNA expression discriminates two types of essential thrombocythemia. Ann Hematol 83:364 370 doi:10.1007/s00277-004-0864-9

8. Teofili L, Pierconti F, Di Febo A, Maggiano N, Vianelli N, Ascani $\mathrm{S}$ et al (2002) The expression pattern of c-mpl in megakaryocytes correlates with thrombotic risk in essential thrombocythemia. Blood 100:714-717 doi:10.1182/blood.V100.2.714

9. Kralovics R, Buser AS, Teo SS, Coers J, Tichelli A, van der Maas AP et al (2003) Comparison of molecular markers in a cohort of patients with chronic myeloproliferative disorders. Blood 102:1869-1871 doi:10.1182/blood-2003-03-0744

10. Carobbio A, Finazzi G, Guerini V, Spinelli O, Delaini F, Marchioli R et al (2007) Leukocytosis is a risk factor for 
thrombosis in essential thrombocythemia: interaction with treatment, standard risk factors, and JAK2 mutation status. Blood 109:2310-2313 doi:10.1182/blood-2006-09-046342

11. Harrison CN (2005) Essential thrombocythaemia: challenges and evidence-based management. Br J Haematol 130:153-165 doi:10.1111/j.1365-2141.2005.05543.x

12. Tefferi A, Thiele J, Orazi A, Kvasnicka HM, Barbui T, Hanson CA et al (2007) Proposals and rationale for revision of the World Health Organization diagnostic criteria for polycythemia vera, essential thrombocythemia, and primary myelofibrosis: recommendations from an ad hoc international expert panel. Blood 110:1092-1097 doi:10.1182/blood-2007-04-083501

13. Thiele J, Kvasnicka HM (2007) Myelofibrosis-what's in a name? Consensus on definition and EUMNET grading. Pathobiology 74:89-96 doi:10.1159/000101708

14. Kvasnicka HM, Thiele J (2006) The impact of clinicopathological studies on staging and survival in essential thrombocythemia, chronic idiopathic myelofibrosis, and polycythemia rubra vera. Semin Thromb Hemost 32:362-371 doi:10.1055/s-2006-942757

15. Thiele J, Kvasnicka HM, Schmitt-Graeff A, Zankovich R, Diehl V (2002) Follow-up examinations including sequential bone marrow biopsies in essential thrombocythemia (ET): a retrospective clinicopathological study of 120 patients. Am J Hematol 70:283-291 doi:10.1002/ajh.10116

16. Buhr T, Georgii A, Choritz H (1993) Myelofibrosis in chronic myeloproliferative disorders. Incidence among subtypes according to the Hannover Classification. Pathol Res Pract 189:121132

17. Kreft A, Buche G, Ghalibafian M, Buhr T, Fischer T, Kirkpatrick CJ (2005) The incidence of myelofibrosis in essential thrombocythaemia, polycythaemia vera and chronic idiopathic myelofibrosis: a retrospective evaluation of sequential bone marrow biopsies. Acta Haematol 113:137-143 doi:10.1159/000083452

18. Wilkins BS, Erber WN, Bareford D, Buck G, Wheatley K, East $\mathrm{CL}$ et al (2008) Bone marrow pathology in essential thrombocythemia: interobserver reliability and utility for identifying disease subtypes. Blood 111:60-70 doi:10.1182/blood-2007-05091850

19. Colwell JA (2006) Aspirin for the primary prevention of cardiovascular events. Timely Top Med Cardiovasc Dis 10:E25

20. Landolfi R, Ciabattoni G, Patrignani P, Castellana MA, Pogliani E, Bizzi B et al (1992) Increased thromboxane biosynthesis in patients with polycythemia vera: evidence for aspirin-suppressible platelet activation in vivo. Blood 80:1965-1971

21. Rocca B, Ciabattoni G, Tartaglione R, Cortelazzo S, Barbui T, Patrono $C$ et al (1995) Increased thromboxane biosynthesis in essential thrombocythemia. Thromb Haemost 74:1225-1230

22. Randi ML, Rossi C, Fabris F, Menapace L, Girolami A (1999) Aspirin seems as effective as myelosuppressive agents in the prevention of rethrombosis in essential thrombocythemia. Clin Appl Thromb Hemost 5:131-135 doi:10.1177/107602969 900500210

23. van Genderen PJ, Mulder PG, Waleboer M, van de Moesdijk D, Michiels JJ (1997) Prevention and treatment of thrombotic complications in essential thrombocythaemia: efficacy and safety of aspirin. Br J Haematol 97:179-184 doi:10.1046/j.13652141.1997.d01-2127.x

24. Michiels JJ, Koudstaal PJ, Mulder AH, van Vliet HH (1993) Transient neurologic and ocular manifestations in primary thrombocythemia. Neurology 43:1107-1110

25. van Genderen PJ, Michiels JJ, van Strik R, Lindemans J, van Vliet HH (1995) Platelet consumption in thrombocythemia complicated by erythromelalgia: reversal by aspirin. Thromb Haemost 73:210-214

26. Landolfi R, Marchioli R, Kutti J, Gisslinger H, Tognoni G, Patrono $\mathrm{C}$ et al (2004) Efficacy and safety of low-dose aspirin in polycythemia vera. N Engl J Med 350:114-124 doi:10.1056/ NEJMoa035572

27. Griesshammer M, Bangerter M, van Vliet HH, Michiels JJ (1997) Aspirin in essential thrombocythemia: status quo and quo vadis. Semin Thromb Hemost 23:371-377

28. Navarra P, Preziosi P (1999) Hydroxyurea: new insights on an old drug. Crit Rev Oncol Hematol 29:249-255 doi:10.1016/ S1040-8428(98)00032-8

29. Cortelazzo S, Finazzi G, Ruggeri M, Vestri O, Galli M, Rodeghiero $\mathrm{F}$ et al (1995) Hydroxyurea for patients with essential thrombocythemia and a high risk of thrombosis. N Engl J Med 332:1132-1136 doi:10.1056/NEJM199504273321704

30. Harrison CN, Campbell PJ, Buck G, Wheatley K, East CL, Bareford D et al (2005) Hydroxyurea compared with anagrelide in high-risk essential thrombocythemia. N Engl J Med 353:3345 doi:10.1056/NEJMoa043800

31. Lofvenberg E, Wahlin A (1988) Management of polycythaemia vera, essential thrombocythaemia and myelofibrosis with hydroxyurea. Eur J Haematol 41:375-381

32. Randi ML, Ruzzon E, Luzzatto G, Tezza F, Girolami A, Fabris F (2005) Safety profile of hydroxyurea in the treatment of patients with Philadelphia-negative chronic myeloproliferative disorders. Haematologica 90:261-262

33. Finazzi G, Ruggeri M, Rodeghiero F, Barbui T (2003) Efficacy and safety of long-term use of hydroxyurea in young patients with essential thrombocythemia and a high risk of thrombosis. Blood 101:3749 doi:10.1182/blood-2003-01-0135

34. Gisslinger H, Kralovics R, Gotic M, Holowiecki J, Penka M, Widmann $R$ et al (2007) Non-inferiority of anagrelide compared to hydroxyurea in newly diagnosed patients with essential thrombocythaemia: the ANAHYDRET study. In: 49th Annual Society of Hematology Annual Meeting, Atlanta, USA, 8-11 December

35. Najean Y, Rain JD, The French Polycythemia Study Group (1997) Treatment of polycythemia vera: use of 32P alone or in combination with maintenance therapy using hydroxyurea in 461 patients greater than 65 years of age. Blood 89:2319-2327

36. Finazzi G, Ruggeri M, Rodeghiero F, Barbui T (2000) Second malignancies in patients with essential thrombocythaemia treated with busulphan and hydroxyurea: long-term follow-up of a randomized clinical trial. $\mathrm{Br} \mathrm{J}$ Haematol 110:577-583 doi: 10.1046/j.1365-2141.2000.02188.x

37. Sterkers Y, Preudhomme C, Lai JL, Demory JL, Caulier MT, Wattel E et al (1998) Acute myeloid leukemia and myelodysplastic syndromes following essential thrombocythemia treated with hydroxyurea: high proportion of cases with $17 \mathrm{p}$ deletion. Blood 91:616-622

38. Randi ML, Fabris F, Girolami A (2002) Second malignancies in patients with essential thrombocythaemia. $\mathrm{Br} \mathrm{J}$ Haematol 116:923-924 doi:10.1111/j.1365-2141.2002.3346_1.x

39. Murphy S, Peterson P, Iland H, Laszlo J (1997) Experience of the Polycythemia Vera Study Group with essential thrombocythemia: a final report on diagnostic criteria, survival, and leukemic transition by treatment. Semin Hematol 34:29-39

40. Gwilt PR, Tracewell WG (1998) Pharmacokinetics and pharmacodynamics of hydroxyurea. Clin Pharmacokinet 34:347-358 doi:10.2165/00003088-199834050-00002

41. Thiele J, Kvasnicka HM, Ollig S, Schmitt-Graff A (2005) Anagrelide does not exert a myelodysplastic effect on megakaryopoiesis: a comparative immunohistochemical and morphometric study with hydroxyurea. Histol Histopathol 20: 1071-1076

42. Bernasconi P, Boni M, Cavigliano PM, Calatroni S, Brusamolino E, Passamonti F et al (2002) Acute myeloid leukemia (AML) having evolved from essential thrombocythemia (ET): distinctive chromosome abnormalities in patients treated with pipobroman 
or hydroxyurea. Leukemia 16:2078-2083 doi:10.1038/sj.leu. 2402638

43. Chim CS, Kwong YL, Lie AK, Ma SK, Chan CC, Wong LG et al (2005) Long-term outcome of 231 patients with essential thrombocythemia: prognostic factors for thrombosis, bleeding, myelofibrosis, and leukemia. Arch Intern Med 165:2651-2658 doi:10.1001/archinte.165.22.2651

44. Fruchtman SM, Mack K, Kaplan ME, Peterson P, Berk PD, Wasserman LR (1997) From efficacy to safety: a Polycythemia Vera Study group report on hydroxyurea in patients with polycythemia vera. Semin Hematol 34:17-23

45. Kiladjian JJ, Rain JD, Bernard JF, Briere J, Chomienne C, Fenaux P (2006) Long-term incidence of hematological evolution in three French prospective studies of hydroxyurea and pipobroman in polycythemia vera and essential thrombocythemia. Semin Thromb Hemost 32:417-421 doi:10.1055/s-2006942762

46. Najean Y, Rain JD (1997) Treatment of polycythemia vera: the use of hydroxyurea and pipobroman in 292 patients under the age of 65 years. Blood 90:3370-3377

47. Stevens MR (1999) Hydroxyurea: an overview. J Biol Regul Homeost Agents 13:172-175

48. Lossos IS, Matzner Y (1995) Hydroxyurea-induced fever: case report and review of the literature. Ann Pharmacother 29:132133

49. Braester A, Quitt M (2000) Hydroxyurea as a cause of drug fever. Acta Haematol 104:50-51 doi:10.1159/000041071

50. Lannemyr O, Kutti J (1999) Hydroxyurea as a cause of drug fever in essential thrombocythaemia. Eur J Haematol 62:354-355

51. Kennedy BJ, Smith LR, Goltz RW (1975) Skin changes secondary to hydroxyurea therapy. Arch Dermatol 111:183-187 doi:10.1001/archderm.111.2.183

52. Dumont-Wallon G, Milpied-Homsi B, Morineau N (2006) Effets secondaires cutanéomuqueux de l'hydroxyurée: étude prospective sur 27 patients. Hematologie 12:262-266

53. Zaccaria E, Cozzani E, Parodi A (2006) Secondary cutaneous effects of hydroxyurea: possible pathogenetic mechanisms. J Dermatolog Treat 17:176-178 doi:10.1080/09546630600780494

54. Best PJ, Petitt RM (1998) Multiple skin cancers associated with hydroxyurea therapy. Mayo Clin Proc 73:961-963

55. Ravandi-Kashani F, Cortes J, Cohen P, Talpaz M, O'Brien S, Markowitz A et al (1999) Cutaneous ulcers associated with hydroxyurea therapy in myeloproliferative disorders. Leuk Lymphoma 35:109-118 doi:10.3109/10428199909145710

56. Gilbert HS (2003) Modern treatment strategies in polycythemia vera. Semin Hematol 40:26-29

57. Barbui T, Finazzi G (2005) When and how to treat essential thrombocythemia. N Engl J Med 353:85-86 doi:10.1056/ NEJMe058093

58. Dingli D, Tefferi A (2005) A critical review of anagrelide therapy in essential thrombocythemia and related disorders. Leuk Lymphoma 46:641-650 doi:10.1080/10428190400029817

59. Barbui T, Barosi G, Grossi A, Gugliotta L, Liberato LN, Marchetti M et al (2004) Practice guidelines for the therapy of essential thrombocythemia. A statement from the Italian Society of Hematology, the Italian Society of Experimental Hematology and the Italian Group for Bone Marrow Transplantation. Haematologica 89:215-232

60. Randi ML, Ruzzon E, Tezza F, Luzzatto G, Fabris F (2005) Toxicity and side effects of hydroxyurea used for primary thrombocythemia. Platelets 16:181-184 doi:10.1080/09537100400020179

61. Barosi G, Besses C, Birgegard G, Briere J, Cervantes F, Finazzi $G$ et al (2007) A unified definition of clinical resistance/ intolerance to hydroxyurea in essential thrombocythemia: results of a consensus process by an international working group. Leukemia 21:277-280 doi:10.1038/sj.1eu.2404473
62. Hong Y, Wang G, Del Arroyo AG, Hernandez J, Skene C, Erusalimsky JD (2006) Comparison between anagrelide and hydroxycarbamide in their activities against haematopoietic progenitor cell growth and differentiation: selectivity of anagrelide for the megakaryocytic lineage. Leukemia 20:1117-1122 doi:10.1038/sj.leu.2404180

63. Birgegard G, Bjorkholm M, Kutti J, Larfars G, Lofvenberg E, Markevarn B et al (2004) Adverse effects and benefits of two years of anagrelide treatment for thrombocythemia in chronic myeloproliferative disorders. Haematologica 89:520-527

64. Fruchtman SM, Petitt RM, Gilbert HS, Fiddler G, Lyne A (2005) Anagrelide: analysis of long-term efficacy, safety and leukemogenic potential in myeloproliferative disorders. Leuk Res 29:481-491 doi:10.1016/j.leukres.2004.10.002

65. Steurer M, Gastl G, Jedrzejczak WW, Pytlik R, Lin W, Schlogl E et al (2004) Anagrelide for thrombocytosis in myeloproliferative disorders: a prospective study to assess efficacy and adverse event profile. Cancer 101:2239-2246 doi:10.1002/cncr.20646

66. Penninga E, Jensen BA, Hansen PB, Clausen NT, MouritsAndersen T, Nielsen OJ et al (2004) Anagrelide treatment in 52 patients with chronic myeloproliferative diseases. Clin Lab Haematol 26:335-340 doi:10.1111/j.1365-2257.2004.00637.x

67. Storen EC, Tefferi A (2001) Long-term use of anagrelide in young patients with essential thrombocythemia. Blood 97:863866 doi:10.1182/blood.V97.4.863

68. Laguna MS, Kornblihtt LI, Marta RF, Michiels JJ, Molinas FC (2000) Effectiveness of anagrelide in the treatment of symptomatic patients with essential thrombocythemia. Clin Appl Thromb Hemost 6:157-161 doi:10.1177/107602960000600307

69. Mills AK, Taylor KM, Wright SJ, Bunce I, Eliadis P, Brigden MC et al (1999) Efficacy, safety and tolerability of anagrelide in the treatment of essential thrombocythaemia. Aust N Z J Med 29:29-35

70. Petrides PE, Beykirch MK, Trapp OM (1998) Anagrelide, a novel platelet lowering option in essential thrombocythaemia: treatment experience in 48 patients in Germany. Eur J Haematol 61:71-76

71. Anagrelide Study Group (1992) Anagrelide, a therapy for thrombocythemic states: experience in 577 patients. Am J Med 92:69-76 doi:10.1016/0002-9343(92)90017-6

72. Petitt RM, Silverstein MN, Petrone ME (1997) Anagrelide for control of thrombocythemia in polycythemia and other myeloproliferative disorders. Semin Hematol 34:51-54

73. Mazzucconi MG, De Sanctis V, Chistolini A, Dragoni F, Mandelli F (1992) Therapy with anagrelide in patients affected by essential thrombocythemia: preliminary results. Haematologica $77: 315-317$

74. Petrides PE (2004) Anagrelide: a decade of clinical experience with its use for the treatment of primary thrombocythaemia. Expert Opin Pharmacother 5:1781-1798 doi:10.1517/14656566. 5.8.1781

75. Barbui T (2004) The leukemia controversy in myeloproliferative disorders: is it a natural progression of disease, a secondary sequela of therapy, or a combination of both. Semin Hematol 41:15-17 doi:10.1053/j.seminhematol.2004.02.006

76. Mazzucconi MG, Redi R, Bernasconi S, Bizzoni L, Dragoni F, Latagliata R et al (2004) A long-term study of young patients with essential thrombocythemia treated with anagrelide. Haematologica 89:1306-1313

77. Zomas A, Marinakis T, Grigoraki V, Gortzolidis G, Arseni P, Skandali A et al (2002) The use anagrelide for control of thrombocytosis in Greek patients with myeloproliferative disorders. Haem 5:320-325

78. Birgegard G (2006) Anagrelide treatment in myeloproliferative disorders. Semin Thromb Hemost 32:260-266 doi:10.1055/s2006-939437 
79. Gilbert HS (2001) Diagnosis and treatment of thrombocythemia in myeloproliferative disorders. Oncology 15:989-996 Williston Park

80. Mazur G, Wrobel T, Podolak-Dawidziak M, KuliszkiewiczJanus M, Potoczek S, Nosol J et al (2004) Anagrelide in the treatment of thrombocythemia essential (ET). Pol Arch Med Wewn 112:1445-1450

81. Tefferi A, Silverstein MN (1998) Treatment of polycythaemia vera and essential thrombocythaemia. Baillieres Clin Haematol 11:769-785 doi:10.1016/S0950-3536(98)80038-3

82. Wadenvik H, Kutti J, Ridell B, Revesz P, Jacobsson S, Magnusson B et al (1991) The effect of alpha-interferon on bone marrow megakaryocytes and platelet production rate in essential thrombocythemia. Blood 77:2103-2108

83. Kiladjian JJ, Cassinat B, Turlure P, Cambier N, Roussel M, Bellucci $S$ et al (2006) High molecular response rate of polycythemia vera patients treated with pegylated interferon alpha-2a. Blood 108:2037-2040 doi:10.1182/blood-2006-03009860

84. Samuelsson J, Mutschler M, Birgegard G, Gram-Hansen P, Bjorkholm M, Pahl HL (2006) Limited effects on JAK2 mutational status after pegylated interferon alpha- $2 \mathrm{~b}$ therapy in polycythemia vera and essential thrombocythemia. Haematologica 91:1281-1282

85. Jones AV, Silver RT, Waghorn K, Curtis C, Kreil S, Zoi K et al (2006) Minimal molecular response in polycythemia vera patients treated with imatinib or interferon alpha. Blood 107:3339-3341 doi:10.1182/blood-2005-09-3917

86. Seewann HL (1993) Interferon therapy in essential thrombocythemia. Wien Med Wochenschr 143:420-424

87. Yataganas X, Meletis J, Plata E, Viniou N, Deligiannis F, Tsekoura C et al (1991) alpha Interferon treatment of essential thrombocythaemia and other myeloproliferative disorders with excessive thrombocytosis. Eur J Cancer 27(Suppl 4):S69-S71

88. Samuelsson J, Hasselbalch H, Bruserud O, Temerinac S, Brandberg Y, Merup M et al (2006) A phase II trial of pegylated interferon alpha- $2 b$ therapy for polycythemia vera and essential thrombocythemia: feasibility, clinical and biologic effects, and impact on quality of life. Cancer 106:2397-2405 doi:10.1002/ cncr.21900

89. Lengfelder E, Griesshammer M, Hehlmann R (1996) Interferonalpha in the treatment of essential thrombocythemia. Leuk Lymphoma 22(Suppl 1):135-142 doi:10.3109/10428199609074371

90. Lengfelder E, Berger U, Hehlmann R (2000) Interferon alpha in the treatment of polycythemia vera. Ann Hematol 79:103-109 doi: $10.1007 / \mathrm{s} 002770050563$

91. Gilbert HS (2002) Other secondary sequelae of treatments for myeloproliferative disorders. Semin Oncol 29:22-27

92. Gisslinger H, Chott A, Scheithauer W, Gilly B, Linkesch W, Ludwig H (1991) Interferon in essential thrombocythaemia. Br J Haematol 79(Suppl 1):42-47 doi:10.1111/j.1365-2141.1991. tb08118.x

93. Çabuk M, Pirildar T, Ceylan C, Koral L, Kirmaz C, Kiliccioglu B et al (2003) Arthritis induced by interferon-alpha therapy in a patient with essential thrombocythemia. Leuk Lymphoma 44:377-378 doi:10.1080/1042819021000029948

94. De Salvo L, Plumacher Z, Gomez O, Weir-Medina J, Paz L, Salas D (1996) Hypertriglyceridemia following treatment with interferon alpha in essential thrombocythemia. Invest Clin 37:177-181

95. Vardizer Y, Linhart Y, Loewenstein A, Garzozi H, Mazawi N, Kesler A (2003) Interferon-alpha-associated bilateral simultaneous ischemic optic neuropathy. J Neuroophthalmol 23:256259 doi:10.1097/00041327-200312000-00003

96. Merup M, Aberg W, Lofvenberg E, Svensson E, Engman K, Paul C et al (2002) Symptoms, symptom distress and health- related quality of life in patients with polycythaemia vera or essential thrombocythaemia during treatment with interferonalpha. Acta Oncol 41:50-55 doi:10.1080/028418602317314064

97. Malek-Ahmadi P, Hilsabeck RC (2007) Neuropsychiatric complications of interferons: classification, neurochemical bases, and management. Ann Clin Psychiatry 19:113-123 doi:10.1080/ 10401230701333038

98. Malek-Ahmadi P (2001) Mood disorders associated with interferon treatment: theoretical and practical considerations. Ann Pharmacother 35:489-495 doi:10.1345/aph.10172

99. Quintas-Cardama A, Kantarjian HM, Giles F, Verstovsek S (2006) Pegylated interferon therapy for patients with Philadelphia chromosome-negative myeloproliferative disorders. Semin Thromb Hemost 32:409-416 doi:10.1055/s-2006-942761

100. Alvarado Y, Cortes J, Verstovsek S, Thomas D, Faderl S, Estrov $Z$ et al (2003) Pilot study of pegylated interferon-alpha $2 b$ in patients with essential thrombocythemia. Cancer Chemother Pharmacol 51:81-86 doi:10.1007/s00280-002-0533-4

101. Langer C, Lengfelder E, Thiele J, Kvasnicka HM, Pahl HL, Beneke $\mathrm{H}$ et al (2005) Pegylated interferon for the treatment of high risk essential thrombocythemia: results of a phase II study. Haematologica 90:1333-1338

102. Jabbour E, Kantarjian H, Cortes J, Thomas D, Garcia-Manero G, Ferrajoli A et al (2007) PEG-IFN-alpha-2b therapy in BCRABL-negative myeloproliferative disorders: final result of a Phase 2 study. Cancer 110:2012-2018 doi:10.1002/cncr.23018

103. Griesshammer M (2006) Risk factors for thrombosis and bleeding and their influence on therapeutic decisions in patients with essential thrombocythemia. Semin Thromb Hemost 32:372-380 doi:10.1055/s-2006-942758

104. Wolanskyj AP, Lasho TL, Schwager SM, McClure RF, Wadleigh M, Lee SJ et al (2005) JAK2 mutation in essential thrombocythaemia: clinical associations and long-term prognostic relevance. Br J Haematol 131:208-213 doi:10.1111/j.1365-2141. 2005.05764.x

105. Tefferi A (2006) Essential thrombocythemia: scientific advances and current practice. Curr Opin Hematol 13:93-98

106. Kittur J, Knudson RA, Lasho TL, Finke CM, Gangat N, Wolanskyj AP et al (2007) Clinical correlates of JAK2V617F allele burden in essential thrombocythemia. Cancer 109:22792284 doi: $10.1002 / \mathrm{cncr} .22663$

107. Finazzi G, Rambaldi A, Guerini V, Carobbo A, Barbui T (2007) Risk of thrombosis in patients with essential thrombocythemia and polycythemia vera according to JAK2 V617F mutation status. Haematologica 92:135-136 doi:10.3324/haematol.10634

108. Hsiao HH, Yang MY, Liu YC, Lee CP, Yang WC, Liu TC et al (2007) The association of JAK2(V617F) mutation and leukocytosis with thrombotic events in essential thrombocythemia. Exp Hematol 35:1704-1707 doi:10.1016/j.exphem.2007.08.011

109. Tefferi A, Elliott M (2007) Thrombosis in myeloproliferative disorders: prevalence, prognostic factors, and the role of leukocytes and JAK2V617F. Semin Thromb Hemost 33:313320 doi:10.1055/s-2007-976165

110. Wolanskyj AP, Schwager SM, McClure RF, Larson DR, Tefferi A (2006) Essential thrombocythemia beyond the first decade: life expectancy, long-term complication rates, and prognostic factors. Mayo Clin Proc 81:159-166

111. Griesshammer M, Struve S, Harrison CM (2006) Essential thrombocythemia/polycythemia vera and pregnancy: the need for an observational study in Europe. Semin Thromb Hemost 32:422-429 doi:10.1055/s-2006-942763

112. Kiladjian JJ, Casadevall N, Vainchenker W, Fenaux P (2007) The first international meeting on V617F JAK2 mutation and its relevance in Philadelphia-negative myeloproliferative disorders. Pathol Biol (Paris) 55:85-87 doi:10.1016/j.patbio.2006. 06.004 